\title{
Efficient Synthesis of the Pentasaccharide Repeating Unit of the O-Antigenic Polysaccharide of Escherichia coli 0166 Strain
}

\author{
Anshupriya Si \\ Anup Kumar Misra* \\ Bose Institute, Division of Molecular Medicine, P-1/12, C.I.T. \\ Scheme VII-M, Kolkata-700054, India \\ akmisra69@gmail.com
}

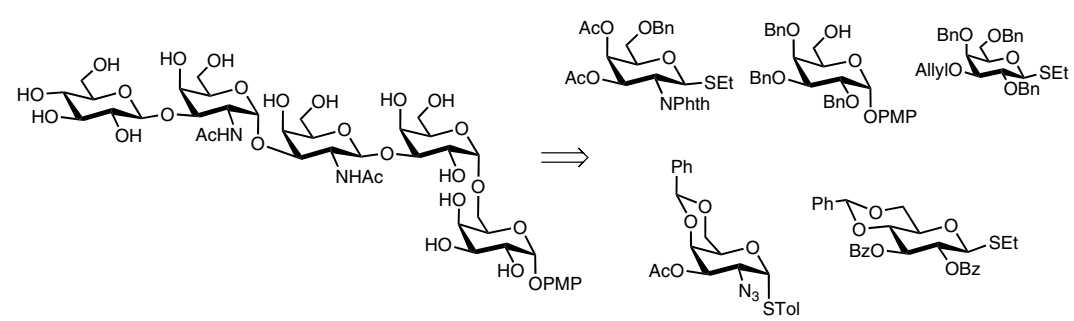

Received: 20.06.2014

Accepted after revision: 06.10.2014

Published online: 10.11 .2014

DOI: 10.1055/s-0034-1378911; Art ID: ss-2014-n0384-op

Abstract An efficient strategy has been developed for the synthesis of the pentasaccharide repeating unit of the cell-wall polysaccharide of Escherichia coli 0166 strain through sequential stereoselective glycosylations of monosaccharide intermediates. All the glycosylation steps were high-yielding with high stereoselectivities.

Key words carbohydrates, glycosylations, glycosides, stereoselectivity, oligosaccharides

Diarrheal outbreaks and gastrointestinal complications are important health problems in developing countries. ${ }^{1}$ In general, intake of contaminated food and water and a lack of adequate sanitation are the leading causes of enteric disorders. ${ }^{2}$ Recently, gastrointestinal infections have also become significant health hazards in developed countries. ${ }^{3}$ Among the several enteropathogenic microbes that are responsible for the diarrheal infections, pathogenic strains of Escherichia coli merit particular attention. These are associated with several gastrointestinal infections, particularly 'travelers' diarrhea' and they can be classified into several pathotypes, such as enteropathogenic, enterohemorrhagic, enterotoxigenic, enteroinvasive, enteroaggregative, or diffusely adherent. ${ }^{4}$ The 0166 strain of E. coli is generally classed as belonging to the enteroaggregative pathotype and causes diarrhea in human by producing a heat-stable enterotoxin. ${ }^{5}$ E. coli 0166 has also been isolated from the environment and from cattle, and has also been classified as an enterohemorrhagic strain. ${ }^{6}$ In 1996, E. coli 0166 was identified as the cause of an outbreak of diarrhea in Japan. ${ }^{7}$
Cell-wall polysaccharides of virulent strains of bacteria play crucial roles in the initial stages of bacterial infections in hosts. As result, researchers have focused attention on the characterization of cell-wall $O$-antigenic polysaccharides from several bacterial strains. Recently, the structure of the pentasaccharide repeating unit of the $O$-antigenic polysaccharide of E. coli 0166 was reported by Ali et al. ${ }^{8}$ This pentasaccharide contains D-glucose, D-galactose, and $\mathrm{N}$-acetyl-D-galactosamine moieties. As the result of the acceleration in the failure of antibiotics to act on multidrugresistant strains of bacteria, the development of alternative approaches to the control of bacterial infections is currently a major area in drug-discovery research. ${ }^{9}$ It is therefore relevant to develop therapeutics based on glycoconjugate derivatives related to cell-wall polysaccharide $O$-antigens, because of their involvement in the process of bacterial infection. Sufficient quantities of oligosaccharides free of biological impurities are required for biological studies, and these cannot readily be isolated from natural sources. Therefore, the development of efficient strategies for chemical synthesis of these oligosaccharides would be extremely useful in providing access to significant quantities of pure oligosaccharides with appropriate structures. In this context, an efficient synthesis of the pentasaccharide repeating unit of the $O$-antigenic polysaccharide of $E$. coli 0166 has been developed.

The target pentasaccharide $\mathbf{1}$ was synthesized as its 4methoxyphenyl glycoside by a series of stereoselective sequential glycosylation reactions of suitably functionalized monosaccharide intermediates. For this purpose, the monosaccharide intermediates $2,3,{ }^{10} 4,{ }^{11} 5,{ }^{12}$ and $\mathbf{6}^{13}$ were prepared by following the methods previously reported (Figure 1). 

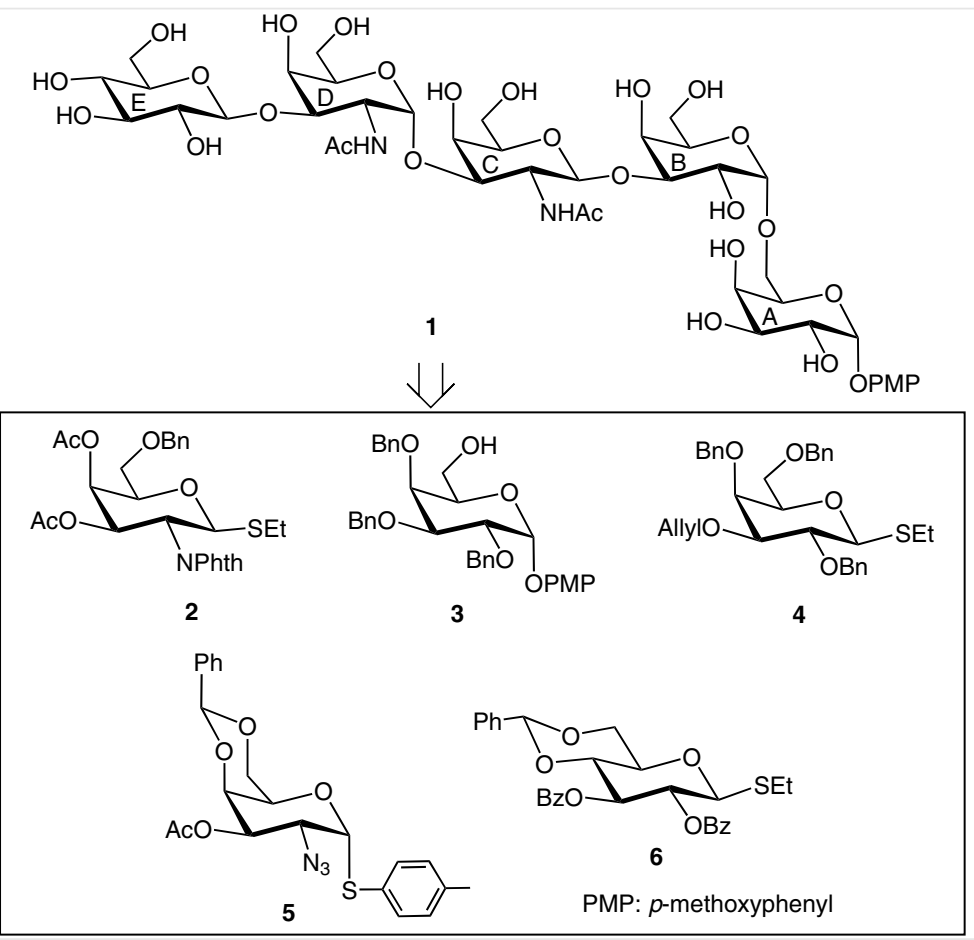

Figure 1 Structures of the synthesized pentasaccharide repeating unit of the $O$-antigenic polysaccharide of E. coli O166 (1) and various monosaccharide intermediates (2-6)

Treatment of the known ethyl 4,6-O-benzylidene-2-deoxy-2-( $N$-phthalimido)-1-thio- $\beta$-D-galactopyranoside $(7)^{14}$ with triethylsilane in the presence of molecular iodine, ${ }^{15}$ followed by acetylation with acetic anhydride and pyridine $^{16}$ gave ethyl 3,4-di-O-acetyl-6-O-benzyl-2-deoxy-2( $N$-phthalimido)-1-thio- $\beta$-D-galactopyranoside (2) in $75 \%$ overall yield (Scheme 1 ).

Stereoselective 1,2-cis glycosylation of the D-galactosyl donor $3^{10}$ with the D-galactosyl acceptor $\mathbf{4}^{11}$ in the presence of $\mathrm{N}$-iodosuccinimide and trimethylsilyl trifluoromethanesulfonate ${ }^{17,18}$ in dichloromethane-diethyl ether gave the disaccharide derivative $\mathbf{8}$ in $72 \%$ yield, together with a minor quantity $(\sim 8 \%)$ of another isomer. Disaccharide 8 was purified by column chromatography and its stereoselective formation was confirmed by spectroscopic analysis. Removal of the allyl ether group from disaccharide 8 by using palladium(II) chloride ${ }^{19}$ gave the partially deprotected disaccharide 9 in 75\% yield. Stereoselective 1,2-trans glycosylation of disaccharide $\mathbf{9}$ with the D-galactosamine donor $\mathbf{2}$ in the presence of $\mathrm{N}$-iodosuccinimide and trimethylsilyl trifluoromethanesulfonate ${ }^{17,18}$ gave the trisaccharide derivative $\mathbf{1 0}$ in $74 \%$ yield. The exclusive formation of compound $\mathbf{1 0}$ was confirmed by NMR spectroscopy. De-O-acetylation of compound 10 with sodium methoxide ${ }^{20}$ gave the trisaccharide diol derivative 11, which was selectively 4-0-acetylated through the formation of an ortho ester ${ }^{21}$ and subsequent acidic hydrolysis to give trisaccharides $\mathbf{1 2}$ in $86 \%$ overall yield. Stereoselective 1,2-cis glycosylation of trisaccharide
12 with the D-galactosamine derivative $5^{12}$ as a glycosyl donor in the presence of $\mathrm{N}$-iodosuccinimide and trimethylsilyl trifluoromethanesulfonate ${ }^{17,18}$ in dichloromethane-diethyl ether gave the tetrasaccharide derivative $\mathbf{1 3}$ in $68 \%$ yield, together with a minor quantity of the trans-glycosylation product ( $10 \%$ ), which was separated by column chromatography. Stereoselective formation of the tetrasaccharide derivative $\mathbf{1 3}$ was confirmed by spectroscopic analysis. Selective removal ${ }^{22}$ of the 3-O-acetyl group from compound 13 by using sodium methoxide left the internally located 4$O$-acetyl group unaffected and gave the tetrasaccharide acceptor 14 in $95 \%$ yield. $N$-Iodosuccinimide-trimethylsilyl trifluoromethanesulfonate-mediated 1,2-trans-glycosylation of tetrasaccharide $\mathbf{1 4}$ with the D-glucose thioglycoside derivative $6^{13}$ in dichloromethane gave the pentasaccharide derivative $\mathbf{1 5}$ in $72 \%$ yield. NMR spectroscopic analysis of compound 15 confirmed that it was formed exclusively. Finally, pentasaccharide $\mathbf{1 5}$ was subjected to a series of reactions to remove the protecting groups completely. These reactions included (a) removal of the $N$-phthaloyl group by treatment with hydrazine monohydrate, ${ }^{23}$ followed by acetylation of the resulting amine using acetic anhydride and pyridine; (b) removal of the benzyl ethers and benzylidene acetals and reduction of the azido group by hydrogenolysis over palladium(II) hydroxide/carbon, ${ }^{24}$ followed by $\mathrm{N}$-acetylation with acetic anhydride in methanol; and (c) removal of the acetyl and benzoyl groups by treatment with sodium methoxide to give the target penta- 


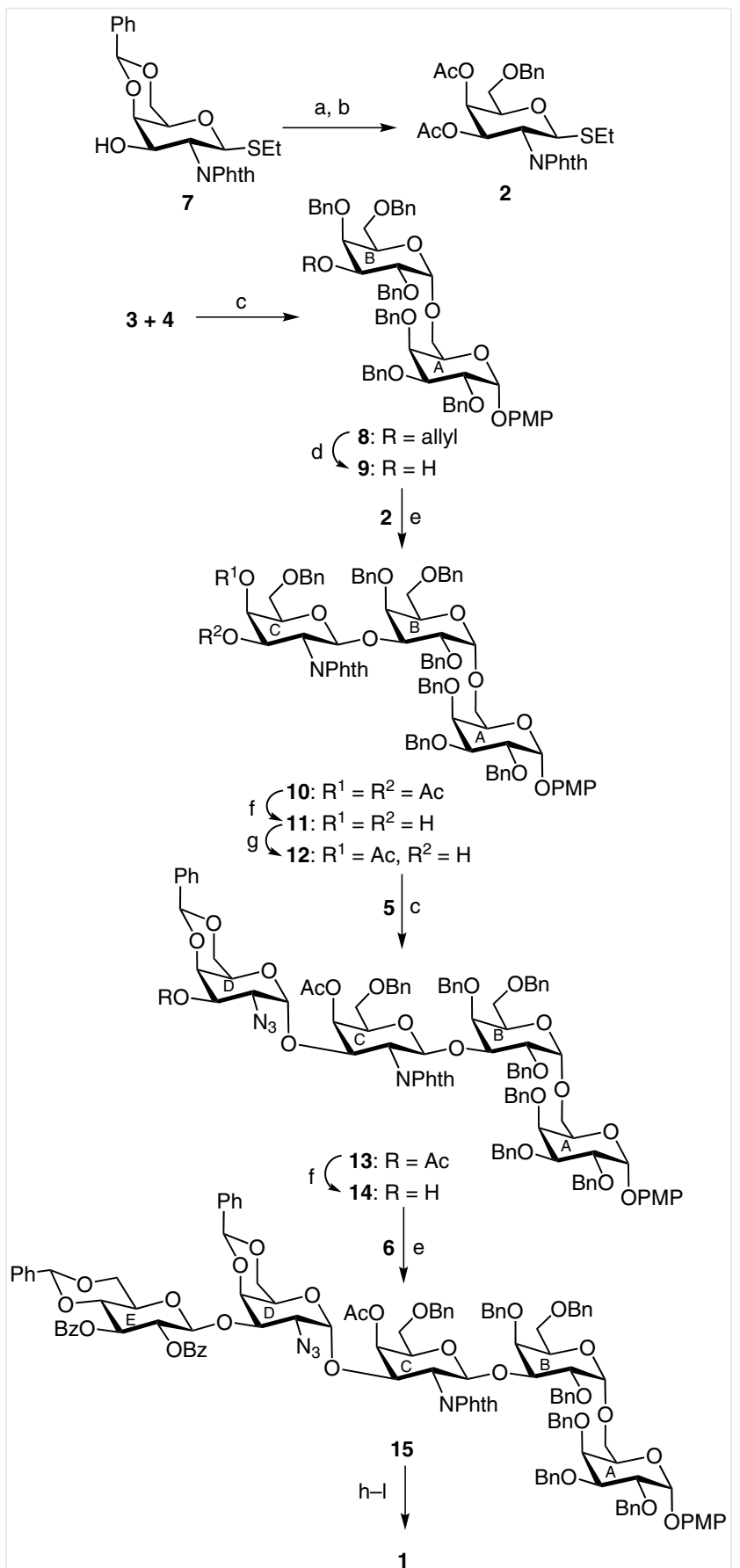

Scheme 1 Reagents and conditions: (a) $\mathrm{Et}_{3} \mathrm{SiH}, \mathrm{MeCN}, \mathrm{I}_{2}, 0-5^{\circ} \mathrm{C}$; (b) $\mathrm{Ac}_{2} \mathrm{O}$, py, r.t., $2 \mathrm{~h}, 75 \%$ (two steps); (c) NIS, TMSOTf, $\mathrm{CH}_{2} \mathrm{Cl}_{2}-\mathrm{Et}_{2} \mathrm{O}$ (1:3), $0{ }^{\circ} \mathrm{C}$, MS- $4 \AA$ $, 45 \mathrm{~min}, 72 \%$ for compound $8,68 \%$ for compound

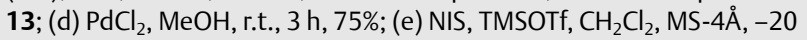
${ }^{\circ} \mathrm{C}, 30 \mathrm{~min}, 74 \%$ for compound $10,72 \%$ for compound 15 ; (f) $0.1 \mathrm{M}$ $\mathrm{NaOMe}, \mathrm{MeOH}$, r.t., $1.5 \mathrm{~h}$, quant for compound $\mathbf{1 1}, 95 \%$ for compound 14; (g) (EtO) ${ }_{3} \mathrm{CMe}$, $\mathrm{TsOH}$, DMF, r.t., 2 h then $\mathrm{H}_{2} \mathrm{O}$, r.t., $30 \mathrm{~min}, 86 \%$; (h) $\mathrm{NH}_{2} \mathrm{NH}_{2} \cdot \mathrm{H}_{2} \mathrm{O}$, EtOH, $80^{\circ} \mathrm{C}, 10$ h; (i) $\mathrm{Ac}_{2} \mathrm{O}$, py, r.t., 1 h; (j) $\mathrm{H}_{2}, 20 \%$ $\mathrm{Pd}(\mathrm{OH})_{2} / \mathrm{C}, \mathrm{MeOH}$, r.t., 15 h; (k) $\mathrm{Ac}_{2} \mathrm{O}, \mathrm{MeOH}$, r.t., 1 h; (l) $0.1 \mathrm{M} \mathrm{NaOMe}$, $\mathrm{MeOH}$, r.t., $1.5 \mathrm{~h}, 54 \%$ (overall). saccharide 1 in 54\% overall yield. The formation of compound 1 was unambiguously confirmed by spectroscopic analysis.

In summary, a straightforward strategy has been developed for the synthesis of the pentasaccharide repeating unit of the 0 -antigen of Escherichia coli 0166 by a series of sequential stereoselective glycosylations of monosaccharide intermediates. The glycosylation steps were high-yielding and gave an excellent stereochemical outcome. Similar reaction conditions were used in each of the glycosylation reactions.

All reactions were monitored by TLC on silica gel coated plates. TLC spots were visualized by spraying the plates with ceric sulfate $[2 \%$ $\mathrm{Ce}\left(\mathrm{SO}_{4}\right)_{2}$ in $2 \mathrm{~N} \mathrm{H}_{2} \mathrm{SO}_{4}$ ] and warming the sprayed TLC plates on a hotplate. Silica gel (230-400 mesh) was used for column chromatography. NMR spectra were recorded on Bruker Avance $500 \mathrm{MHz}$ spectrometer with $\mathrm{CDCl}_{3}$ as solvent and TMS as the internal reference, unless stated otherwise. Chemical shifts $(\delta=)$ are expressed in ppm. Complete assignment of the ${ }^{1} \mathrm{H}$ and ${ }^{13} \mathrm{C}$ NMR spectra was carried out by means of a standard set of NMR experiments, e.g. ${ }^{1} \mathrm{H}$ NMR, ${ }^{13} \mathrm{C}$ NMR, ${ }^{13} \mathrm{C}$ DEPT 135, 2D COSY, and 2D HSQC. MALDI mass spectra were recorded on a Bruker mass spectrometer. Optical rotations were recorded in a JASCO P-2000 polarimeter. Commercially available grades of organic solvents of adequate purity were used in all reactions.

Ethyl 3,4-Di-O-acetyl-6-O-benzyl-2-deoxy-2-( $N$-phthalimido)-1thio- $\beta$-D-galactopyranoside (2)

$\mathrm{Et}_{3} \mathrm{SiH}(1.8 \mathrm{~mL}, 11.27 \mathrm{mmol})$ and $\mathrm{I}_{2}(250 \mathrm{mg}, 0.98 \mathrm{mmol})$ were added sequentially to a solution of monosaccharide derivative 7 (2 g, 4.53 $\mathrm{mmol})$ in $\mathrm{MeCN}(10 \mathrm{~mL})$ at $0-5{ }^{\circ} \mathrm{C}$, and the mixture was stirred at $0-5$ ${ }^{\circ} \mathrm{C}$ for $40 \mathrm{~min}$. The mixture was then diluted with $\mathrm{CH}_{2} \mathrm{Cl}_{2}(100 \mathrm{~mL})$ and washed successively with $5 \%$ aq $\mathrm{Na}_{2} \mathrm{~S}_{2} \mathrm{O}_{3}(50 \mathrm{~mL})$ and $\mathrm{H}_{2} \mathrm{O}(100 \mathrm{~mL})$, then dried $\left(\mathrm{Na}_{2} \mathrm{SO}_{4}\right)$ and concentrated. A solution of the crude product in $\mathrm{Ac}_{2} \mathrm{O}(5 \mathrm{~mL})$ and pyridine $(5 \mathrm{~mL})$ was kept at r.t. for $2 \mathrm{~h}$. The reagents were removed under reduced pressure and the crude product was purified by chromatography [silica gel, hexane-EtOAc (3:1)] to give a yellow oil; yield: $1.8 \mathrm{~g}(75 \%)$; $[\alpha]_{\mathrm{D}}{ }^{23}+43\left(\mathrm{c} 1.0, \mathrm{CHCl}_{3}\right)$.

IR (neat): 3024, 1736, 1515, 1372, 1216, 1096, $766 \mathrm{~cm}^{-1}$.

${ }^{1} \mathrm{H}$ NMR (500 MHz, $\mathrm{CDCl}_{3}$ ): $\delta=7.83-7.21(\mathrm{~m}, 9 \mathrm{H}, \mathrm{Ar}-\mathrm{H}), 5.79(\mathrm{dd}$, $J=11.0,3.0 \mathrm{~Hz}, 1 \mathrm{H}, \mathrm{H}-3$ ), 5.55 (d, $J=2.0 \mathrm{~Hz}, 1 \mathrm{H}, \mathrm{H}-4), 5.44$ (d, $J=10.5$ $\mathrm{Hz}, 1 \mathrm{H}, \mathrm{H}-1$ ), 4.57 (d, J= $\left.12.0 \mathrm{~Hz}, 1 \mathrm{H}, \mathrm{PhCH}_{2}\right), 4.53(\mathrm{t}, J=10.5 \mathrm{~Hz}, 1 \mathrm{H}$, $\mathrm{H}-2$ ), 4.43 (d, J= 12.0 Hz, $1 \mathrm{H}, \mathrm{PhCH}_{2}$ ), 4.07-4.04 (m, $\left.1 \mathrm{H}, \mathrm{H}-5\right), 3.59-$ $3.56\left(\mathrm{~m}, 1 \mathrm{H}, \mathrm{H}-6_{\mathrm{a}}\right), 3.50-3.46\left(\mathrm{~m}, 1 \mathrm{H}, \mathrm{H}-6_{\mathrm{b}}\right), 2.71-2.63(\mathrm{~m}, 2 \mathrm{H}$, $\left.\mathrm{SCH}_{2} \mathrm{CH}_{3}\right), 2.08-1.82\left(2 \mathrm{~s}, 6 \mathrm{H}, 2 \mathrm{COCH}_{3}\right), 1.26(\mathrm{t}, J=7.4 \mathrm{~Hz}, 3 \mathrm{H}$, $\left.\mathrm{SCH}_{2} \mathrm{CH}_{3}\right)$.

${ }^{13} \mathrm{C}$ NMR $\left(125 \mathrm{MHz}, \mathrm{CDCl}_{3}\right): \delta=170.0,169.5\left(2 \mathrm{COCH}_{3}\right), 167.8,167.3$ (PhthCO), 137.6-123.6 (m, Ar-C), 81.5 (C-1), $75.9(\mathrm{C}-3), 73.5\left(\mathrm{PhCH}_{2}\right)$, 69.0 (C-4), 67.6 (C-6), 67.4 (C-5), $50.3(\mathrm{C}-2), 24.4\left(\mathrm{SCH}_{2} \mathrm{CH}_{3}\right), 20.7,20.5$ $\left(2 \mathrm{COCH}_{3}\right), 14.9\left(\mathrm{SCH}_{2} \mathrm{CH}_{3}\right)$.

ESI-MS: $550.1[\mathrm{M}+\mathrm{Na}]^{+}$.

Anal. Calcd for $\mathrm{C}_{27} \mathrm{H}_{29} \mathrm{NO}_{8} \mathrm{~S}$ (527.16): C, 61.47; H, 5.54. Found: C, 61.30; H, 5.70. 


\section{4-Methoxyphenyl (3-0-Allyl-2,4,6-tri-O-benzyl- $\alpha$-D-galactopyra- nosyl)-(1 $\rightarrow$ 6)-2,3,4-tri-0-benzyl- $\alpha$-D-galactopyranoside (8)}

MS-4Å ( $3 \mathrm{~g}$ ) were added to a solution of compound 3 (1.5 g, 2.69 mmol) and compound $4(1.6 \mathrm{~g}, 3.0 \mathrm{mmol})$ in anhyd $1: 3 \mathrm{CH}_{2} \mathrm{Cl}_{2}-\mathrm{Et}_{2} \mathrm{O}$ $(20 \mathrm{~mL})$, and the mixture was cooled to $0{ }^{\circ} \mathrm{C}$ under argon. The cooled mixture was treated with NIS $(0.7 \mathrm{~g}, 3.11 \mathrm{mmol})$ and TMSOTf $(15 \mu \mathrm{L})$ then stirred at $0{ }^{\circ} \mathrm{C}$ for $45 \mathrm{~min}$. The mixture was then diluted with $\mathrm{CH}_{2} \mathrm{Cl}_{2}(100 \mathrm{~mL})$ and washed successively with $5 \%$ aq $\mathrm{Na}_{2} \mathrm{~S}_{2} \mathrm{O}_{3}(50 \mathrm{~mL})$, sat. aq $\mathrm{NaHCO}_{3}(100 \mathrm{~mL})$, and $\mathrm{H}_{2} \mathrm{O}(100 \mathrm{~mL})$. The organic phase was then dried $\left(\mathrm{Na}_{2} \mathrm{SO}_{4}\right)$ and concentrated under reduced pressure to give a crude product that was purified by chromatography [silica gel, hexane-EtOAc (4:1)] to give a colorless oil; yield: $2 \mathrm{~g}(72 \%) ;[\alpha]_{\mathrm{D}}{ }^{23}+60(c$ $\left.1.0, \mathrm{CHCl}_{3}\right)$.

IR (neat): 3025, 2363, 1719, 1509, 1387, 1216, 1097, $758 \mathrm{~cm}^{-1}$.

${ }^{1} \mathrm{H}$ NMR $\left(500 \mathrm{MHz}, \mathrm{CDCl}_{3}\right): \delta=7.39-7.20(\mathrm{~m}, 30 \mathrm{H}, \mathrm{Ar}-\mathrm{H}), 6.98(\mathrm{~d}, J=$ $9.0 \mathrm{~Hz}, 2 \mathrm{H}, \mathrm{Ar}-\mathrm{H}), 6.74(\mathrm{~d}, J=9.0 \mathrm{~Hz}, 2 \mathrm{H}, \mathrm{Ar}-\mathrm{H}), 5.96-5.86(\mathrm{~m}, 1 \mathrm{H}$, $\left.\mathrm{CH}=\mathrm{CH}_{2}\right), 5.37\left(\mathrm{~d}, \mathrm{~J}=2.5 \mathrm{~Hz}, 1 \mathrm{H}, \mathrm{H}-1_{\mathrm{A}}\right), 5.32-5.28\left(\mathrm{~m}, 1 \mathrm{H}, \mathrm{CH}=\mathrm{CH}_{2}\right)$, 5.15-5.13 (m, $\left.1 \mathrm{H}, \mathrm{CH}=\mathrm{CH}_{2}\right), 4.95-4.67(7 \mathrm{~d}, J=11.0 \mathrm{~Hz}$ each, $7 \mathrm{H}$, $\left.\mathrm{PhCH}_{2}\right), 4.65\left(\mathrm{~d}, J=3.5 \mathrm{~Hz}, 1 \mathrm{H}, \mathrm{H}-1_{\mathrm{B}}\right), 4.58-4.34(5 \mathrm{~d}, J=11.0 \mathrm{~Hz}$ each, 5 $\mathrm{H}, \mathrm{PhCH}_{2}$ ), 4.14-4.11 (m, $5 \mathrm{H}, \mathrm{H}-2_{\mathrm{A}}, \mathrm{H}-5_{\mathrm{A}}, \mathrm{H}-5_{\mathrm{B}}, \mathrm{OCH}_{2}=\mathrm{CH}$ ), 3.94 (br s, 1 $\left.\mathrm{H}, \mathrm{H}-4_{\mathrm{A}}\right), 3.90-3.88$ ( $\left.\mathrm{m}, 2 \mathrm{H}, \mathrm{H}-2_{\mathrm{B}}, \mathrm{H}-3_{\mathrm{A}}\right), 3.85$ (br s, $\left.1 \mathrm{H}, \mathrm{H}-4_{\mathrm{B}}\right), 3.71-$ $3.65\left(\mathrm{~m}, 1 \mathrm{H}, \mathrm{H}-\mathrm{6}_{\mathrm{aA}}\right), 3.67\left(\mathrm{~s}, 2 \mathrm{H}, \mathrm{OCH}_{3}\right), 3.58-3.53\left(\mathrm{~m}, 2 \mathrm{H}, \mathrm{H}-3_{\mathrm{B}}, \mathrm{H}-\right.$ $\left.6_{\mathrm{aB}}\right), 3.49-3.46$ (dd, $\left.J=12.0,5.5 \mathrm{~Hz}, 1 \mathrm{H}, \mathrm{H}-6_{\mathrm{bB}}\right), 3.41-3.39$ (dd, $J=12.0$, $\left.4.5 \mathrm{~Hz}, 1 \mathrm{H}, \mathrm{H}-6_{\mathrm{bA}}\right)$.

${ }^{13} \mathrm{C}$ NMR $\left(125 \mathrm{MHz}, \mathrm{CDCl}_{3}\right): \delta=154.8-114.4\left(\mathrm{~m}, \mathrm{Ar}-\mathrm{C}, \mathrm{CH}_{2}=\mathrm{CH}\right), 98.0$ $\left(C-1_{B}\right), 96.9\left(C-1_{A}\right), 78.9\left(C-5_{A}\right), 78.7\left(C-5_{B}\right), 76.4\left(C-3_{B}\right), 76.1\left(C-3_{A}\right)$, $75.4\left(\mathrm{C}-4_{\mathrm{B}}\right), 74.7\left(2 \mathrm{C}, 2 \mathrm{PhCH}_{2}\right), 74.6\left(\mathrm{C}-4_{\mathrm{A}}\right), 73.6\left(\mathrm{PhCH}_{2}\right), 73.4$ $\left(\mathrm{PhCH}_{2}\right), 73.3\left(2 \mathrm{C}, 2 \mathrm{PhCH}_{2}\right), 71.4\left(\mathrm{OCH}_{2}\right), 70.3\left(\mathrm{C}-2_{\mathrm{A}}\right), 69.1\left(\mathrm{C}-2_{\mathrm{B}}\right), 68.6$ $\left(\mathrm{C}-6_{\mathrm{B}}\right), 67.4\left(\mathrm{C}-6_{\mathrm{A}}\right), 55.3\left(\mathrm{OCH}_{3}\right)$.

MALDI-MS: $1051.4[\mathrm{M}+\mathrm{Na}]^{+}$.

Anal. Calcd for $\mathrm{C}_{64} \mathrm{H}_{68} \mathrm{O}_{12}$ (1028.47): C, 74.69; $\mathrm{H}, 6.66$. Found: C, 74.54; $\mathrm{H}, 6.80$.

\section{4-Methoxyphenyl (2,4,6-Tri-0-benzyl- $\alpha$-D-galactopyranosyl)- $(\mathbf{1} \rightarrow \mathbf{6})$-2,3,4-tri- 0 -benzyl- $\alpha$-D-galactopyranoside (9)}

$\mathrm{PdCl}_{2}(125 \mathrm{mg}, 0.70 \mathrm{mmol})$ was added to a solution of compound $\mathbf{8}$ $(1.8 \mathrm{~g}, 1.75 \mathrm{mmol})$ in anhyd $\mathrm{MeOH}(25 \mathrm{~mL})$, and the mixture was stirred at r.t. for $3 \mathrm{~h}$. The mixture was then concentrated under reduced pressure and purified by chromatography [silica gel, hexaneEtOAc (4:1)] to give a colorless oil; yield: $1.3 \mathrm{~g} \mathrm{(75 \% );}[\alpha]_{\mathrm{D}}^{23}+95$ (c 1.0, $\left.\mathrm{CHCl}_{3}\right)$.

IR (neat): 3020, 2362, 1722, 1599, 1513, 1426, 1217, 1046, 927, 761 $\mathrm{cm}^{-1}$.

${ }^{1} \mathrm{H}$ NMR $\left(500 \mathrm{MHz}, \mathrm{CDCl}_{3}\right): \delta=7.39-7.24(\mathrm{~m}, 30 \mathrm{H}, \mathrm{Ar}-\mathrm{H}), 6.97(\mathrm{~d}, J=$ $9.0 \mathrm{~Hz}, 2 \mathrm{H}, \mathrm{Ar}-\mathrm{H}), 6.72(\mathrm{~d}, J=9.0 \mathrm{~Hz}, 2 \mathrm{H}, \mathrm{Ar}-\mathrm{H}), 5.33(\mathrm{~d}, J=2.5 \mathrm{~Hz}, 1 \mathrm{H}$, $\left.\mathrm{H}-1_{\mathrm{A}}\right), 4.96-4.70\left(6 \mathrm{~d}, J=11.0 \mathrm{~Hz}\right.$ each, $\left.6 \mathrm{H}, \mathrm{PhCH}_{2}\right), 4.67$ (d, $J=2.5 \mathrm{~Hz}$, $\left.1 \mathrm{H}, \mathrm{H}-1_{\mathrm{B}}\right), 4.60-4.34\left(6 \mathrm{~d}, J=11.0 \mathrm{~Hz}\right.$ each, $\left.6 \mathrm{H}, \mathrm{PhCH}_{2}\right), 4.13-4.10(\mathrm{~m}$, $3 \mathrm{H}, \mathrm{H}-2_{\mathrm{A}}, \mathrm{H}-5_{\mathrm{A}}, \mathrm{H}-5_{\mathrm{B}}$ ), 3.92 (br s, $1 \mathrm{H}, \mathrm{H}-4_{\mathrm{A}}$ ), 3.89-3.83 (m, $2 \mathrm{H}, \mathrm{H}-2_{\mathrm{B}}$, $\left.\mathrm{H}-3_{\mathrm{A}}\right), 3.79$ (br s, $\left.1 \mathrm{H}, \mathrm{H}-4_{\mathrm{B}}\right), 3.70\left(\mathrm{~s}, 3 \mathrm{H}, \mathrm{OCH}_{3}\right), 3.68-3.66(\mathrm{~m}, 2 \mathrm{H}, \mathrm{H}-$ $\left.3_{\mathrm{B},} \mathrm{H}-6_{\mathrm{aA}}\right), 3.52-3.48\left(\mathrm{~m}, 2 \mathrm{H}, \mathrm{H}-6_{\mathrm{abB}}\right), 3.35-3.32\left(\mathrm{~m}, 1 \mathrm{H}, \mathrm{H}-6_{\mathrm{bA}}\right)$.

${ }^{13} \mathrm{C}$ NMR $\left(125 \mathrm{MHz}, \mathrm{CDCl}_{3}\right): \delta=155.1-114.4(\mathrm{~m}, \mathrm{Ar}-\mathrm{C}), 97.5\left(\mathrm{C}-1_{\mathrm{B}}\right)$, 97.1 $\left(\mathrm{C}-1_{\mathrm{A}}\right), 78.9\left(\mathrm{C}-5_{\mathrm{A}}\right), 77.3\left(\mathrm{C}-5_{\mathrm{B}}\right), 76.7\left(\mathrm{C}-4_{\mathrm{B}}\right), 76.4\left(\mathrm{C}-3_{\mathrm{A}}\right), 75.4(\mathrm{C}-$ $4 \mathrm{~A}), 75.1\left(\mathrm{PhCH}_{2}\right), 74.6\left(\mathrm{PhCH}_{2}\right), 73.4\left(2 \mathrm{C}, 2 \mathrm{PhCH}_{2}\right), 73.3\left(\mathrm{PhCH}_{2}\right), 72.7$ $\left(\mathrm{PhCH}_{2}\right), 70.2\left(\mathrm{C}-3_{\mathrm{B}}\right), 69.9\left(\mathrm{C}-2_{\mathrm{A}}\right), 68.9\left(\mathrm{C}-2_{\mathrm{B}}\right), 68.6\left(\mathrm{C}-6_{\mathrm{B}}\right), 67.3\left(\mathrm{C}-6_{\mathrm{A}}\right)$, $55.4\left(\mathrm{OCH}_{3}\right)$.

MALDI-MS: $1011.4[\mathrm{M}+\mathrm{Na}]^{+}$.

Anal. Calcd for $\mathrm{C}_{61} \mathrm{H}_{64} \mathrm{O}_{12}$ (988.44): C, 74.07; H, 6.52. Found: C, 73.87; H, 6.70 .
4-Methoxyphenyl [3,4-Di-O-acetyl-6-O-benzyl-2-deoxy-2-( $N$ phthalimido)- $\beta$-D-galactopyranosyl]-( $1 \rightarrow 3)-(2,4,6$-tri- 0 -benzyl- $\alpha$ D-galactopyranosyl)-( $1 \rightarrow 6)-2,3,4$-tri- 0 -benzyl- $\alpha$-D-galactopyranoside (10)

MS-4Å ( $1 \mathrm{~g}$ ) were added to a solution of compound $\mathbf{9}$ (1.2 g, 1.21 mmol) and compound 2 (960 $\mathrm{mg}, 1.82 \mathrm{mmol})$ in anhyd $\mathrm{CH}_{2} \mathrm{Cl}_{2}(10$ $\mathrm{mL}$ ), and the mixture was cooled to $-20{ }^{\circ} \mathrm{C}$ under argon. NIS (560 mg, $2.49 \mathrm{mmol})$ and TMSOTf $(10 \mu \mathrm{L})$ were added, and the cooled mixture was stirred at $-20^{\circ} \mathrm{C}$ for $30 \mathrm{~min}$. The mixture was then diluted with $\mathrm{CH}_{2} \mathrm{Cl}_{2}(100 \mathrm{~mL})$ and washed successively with $5 \%$ aq $\mathrm{Na}_{2} \mathrm{~S}_{2} \mathrm{O}_{3}(50 \mathrm{~mL})$, sat. aq $\mathrm{NaHCO}_{3}(100 \mathrm{~mL})$, and $\mathrm{H}_{2} \mathrm{O}(100 \mathrm{~mL})$. The organic phase was dried $\left(\mathrm{Na}_{2} \mathrm{SO}_{4}\right)$ and concentrated under reduced pressure to give a crude product that was purified by chromatography [silica gel, hexane-EtOAc (4:1)] to give white solid; yield: $1.3 \mathrm{~g}$ (74\%); $\mathrm{mp} 74-75{ }^{\circ} \mathrm{C}$ $(\mathrm{EtOH}) ;[\alpha]_{D}^{23}+33\left(c 1.0, \mathrm{CHCl}_{3}\right)$.

IR (KBr): 3020, 2362, 1719, 1610, 1511, 1216, 1098, 1400, $761 \mathrm{~cm}^{-1}$.

${ }^{1} \mathrm{H} \mathrm{NMR}\left(500 \mathrm{MHz}, \mathrm{CDCl}_{3}\right): \delta=7.48-6.77(\mathrm{~m}, 43 \mathrm{H}, \mathrm{Ar}-\mathrm{H}), 5.87(\mathrm{dd}, J=$ 11.0, 3.5 Hz, $1 \mathrm{H}, \mathrm{H}-3_{\mathrm{C}}$ ), 5.58 (d, J = 3.0 Hz, $1 \mathrm{H}, \mathrm{H}-4_{\mathrm{C}}$ ), 5.55 (d, J= $8.0 \mathrm{~Hz}$, $\left.1 \mathrm{H}, \mathrm{H}-1_{\mathrm{C}}\right), 5.28\left(\mathrm{~d}, J=2.5 \mathrm{~Hz}, 1 \mathrm{H}, \mathrm{H}-1_{\mathrm{A}}\right), 4.95-4.58(7 \mathrm{~d}, J=11.5 \mathrm{~Hz}$ each, $\left.7 \mathrm{H}, \mathrm{PhCH}_{2}\right), 4.56\left(\mathrm{t}, J=8.5 \mathrm{~Hz}\right.$ each, $\left.1 \mathrm{H}, \mathrm{H}-2_{\mathrm{c}}\right), 4.51(\mathrm{~d}, J=11.5$ $\mathrm{Hz}, 1 \mathrm{H}, \mathrm{PhCH}_{2}$ ), 4.38-4.35 (m, $3 \mathrm{H}, \mathrm{PhCH}_{2}$ ), 4.33 (br s, $1 \mathrm{H}, \mathrm{H}-1_{\mathrm{B}}$ ), 4.26$4.16\left(\mathrm{~m}, 3 \mathrm{H}, \mathrm{PhCH}_{2}\right), 4.09-3.99\left(\mathrm{~m}, 4 \mathrm{H}, \mathrm{H}-2_{\mathrm{A}}, \mathrm{H}-3_{\mathrm{B}}, \mathrm{H}-5_{\mathrm{A}}, \mathrm{H}-5_{\mathrm{B}}\right), 3.98-$ $3.92\left(\mathrm{~m}, 2 \mathrm{H}, \mathrm{H}-3_{\mathrm{A}}, \mathrm{H}-4_{\mathrm{A}}\right), 3.87-3.82\left(\mathrm{~m}, 2 \mathrm{H}, \mathrm{H}-4_{\mathrm{B}}, \mathrm{H}-5_{\mathrm{C}}\right), 3.75(\mathrm{~s}, 3 \mathrm{H}$, $\left.\mathrm{OCH}_{3}\right), 3.65\left(\mathrm{dd}, J=10.0,3.5 \mathrm{~Hz}, 1 \mathrm{H}, \mathrm{H}-2_{\mathrm{B}}\right), 3.56-3.51\left(\mathrm{~m}, 3 \mathrm{H}, \mathrm{H}-6_{\mathrm{aA}}\right.$, H- $6_{\mathrm{abc}}$ ), 3.42-3.28 (m, $\left.2 \mathrm{H}, \mathrm{H}-6_{\mathrm{abB}}\right), 3.24$ (dd, $J=12.0,5.5 \mathrm{~Hz}, 1 \mathrm{H}, \mathrm{H}-$ $\left.6_{\mathrm{bA}}\right), 2.02,1.84\left(2 \mathrm{~s}, 6 \mathrm{H}, 2 \mathrm{COCH}_{3}\right)$.

${ }^{13} \mathrm{C}$ NMR $\left(125 \mathrm{MHz}, \mathrm{CDCl}_{3}\right): \delta=169.5,169.4\left(2 \mathrm{COCH}_{3}\right), 167.7,167.4$ (PhthCO), 155.0-114.4 (m, Ar-C), 99.7 (C-1 $\left.1_{\mathrm{C}}\right), 97.7\left(\mathrm{C}-1_{\mathrm{A}}\right), 97.6\left(\mathrm{C}-1_{\mathrm{B}}\right)$, $78.8\left(2 \mathrm{C}, \mathrm{C}-5_{\mathrm{A}}, \mathrm{C}-5_{\mathrm{B}}\right), 76.7\left(\mathrm{C}-3_{\mathrm{A}}\right), 76.3\left(\mathrm{C}-2_{\mathrm{B}}\right), 75.5\left(\mathrm{C}-3_{\mathrm{B}}\right), 75.2\left(\mathrm{C}-2_{\mathrm{A}}\right)$, $74.5\left(\mathrm{PhCH}_{2}\right), 74.4\left(\mathrm{PhCH}_{2}\right), 73.4\left(\mathrm{PhCH}_{2}\right), 73.3\left(\mathrm{PhCH}_{2}\right), 73.2\left(\mathrm{PhCH}_{2}\right)$, $73.1\left(\mathrm{PhCH}_{2}\right), 72.6\left(\mathrm{PhCH}_{2}\right), 71.6\left(\mathrm{C}-4_{\mathrm{B}}\right), 69.9\left(\mathrm{C}-5_{\mathrm{C}}\right), 69.0\left(2 \mathrm{C}, \mathrm{C}-4_{\mathrm{A}}, \mathrm{C}-\right.$ $\left.6_{\mathrm{B}}\right), 67.9\left(\mathrm{C}-3_{\mathrm{C}}\right), 67.4\left(\mathrm{C}-4_{\mathrm{C}}\right), 67.2\left(\mathrm{C}-6_{\mathrm{A}}\right), 67.1\left(\mathrm{C}-6_{\mathrm{C}}\right), 55.5\left(\mathrm{OCH}_{3}\right), 51.9$ $\left(\mathrm{C}-2_{\mathrm{C}}\right), 20.6,20.5\left(2 \mathrm{COCH}_{3}\right)$.

MALDI-MS: $1476.5[\mathrm{M}+\mathrm{Na}]^{+}$.

Anal. Calcd for $\mathrm{C}_{86} \mathrm{H}_{87} \mathrm{NO}_{20}$ (1453.58): C, 71.01; H, 6.03. Found: $\mathrm{C}$, $70.84 ; \mathrm{H}, 5.85$.

4-Methoxyphenyl [4-O-Acetyl-6-O-benzyl-2-deoxy-2-( $N$-phthalimido)- $\beta$-D-galactopyranosyl]-(1 $\rightarrow 3)-(2,4,6$-tri- 0 -benzyl- $\alpha$-D-galactopyranosyl)-( $1 \rightarrow 6)-2,3,4$-tri-O-benzyl- $\alpha$-D-galactopyranoside (12)

A solution of compound $\mathbf{1 0}(1.2 \mathrm{~g}, 0.82 \mathrm{mmol})$ in $0.1 \mathrm{M}$ methanolic NaOMe $(20 \mathrm{~mL})$ was stirred at r.t. for $1.5 \mathrm{~h}$, then neutralized with Dowex 50W X8 $\left(\mathrm{H}^{+}\right)$resin, filtered, and concentrated under reduced pressure. A solution of the crude product 11in DMF $(5 \mathrm{~mL})$ was treated with $\mathrm{MeC}(\mathrm{OEt})_{3}(0.6 \mathrm{~mL}, 3.27 \mathrm{mmol})$ and $\mathrm{TsOH}(100 \mathrm{mg})$ and then stirred at r.t. for $2 \mathrm{~h} . \mathrm{H}_{2} \mathrm{O}(2 \mathrm{~mL})$ was added and the mixture was stirred at r.t. for a further $30 \mathrm{~min}$. The mixture was diluted with $\mathrm{H}_{2} \mathrm{O}$ $(100 \mathrm{~mL})$ and extracted with $\mathrm{CH}_{2} \mathrm{Cl}_{2}(100 \mathrm{~mL})$. The organic layer was washed successively with sat. aq $\mathrm{NaHCO}_{3}(100 \mathrm{~mL})$ and $\mathrm{H}_{2} \mathrm{O}(100 \mathrm{~mL})$, then dried $\left(\mathrm{Na}_{2} \mathrm{SO}_{4}\right)$ and concentrated. The crude product was purified by chromatography [silica gel, hexane-EtOAc (4:1)] to give a colorless oil; yield: $1 \mathrm{~g}$ (86\%, two steps); $[\alpha]_{\mathrm{D}}^{23}+35\left(\mathrm{c} 1.0, \mathrm{CHCl}_{3}\right)$.

IR (neat): 2929, 2365, 1719, 1629, 1386, 1227, 1099, $768 \mathrm{~cm}^{-1}$.

${ }^{1} \mathrm{H}$ NMR $\left(500 \mathrm{MHz}, \mathrm{CDCl}_{3}\right): \delta=7.46-6.75(\mathrm{~m}, 43 \mathrm{H}, \mathrm{Ar}-\mathrm{H}), 5.48(\mathrm{~d}, J=$ $\left.8.5 \mathrm{~Hz}, 1 \mathrm{H}, \mathrm{H}-1_{\mathrm{C}}\right), 5.44\left(\mathrm{~d}, J=3.0 \mathrm{~Hz}, 1 \mathrm{H}, \mathrm{H}-4_{\mathrm{C}}\right), 5.27(\mathrm{~d}, J=2.0 \mathrm{~Hz}, 1 \mathrm{H}$, $\left.\mathrm{H}-1_{\mathrm{A}}\right), 4.93-4.49\left(10 \mathrm{~d}, J=11.5 \mathrm{~Hz}\right.$ each, $\left.10 \mathrm{H}, \mathrm{PhCH}_{2}\right), 4.41$ (d, $J=2.5$ $\left.\mathrm{Hz}, 1 \mathrm{H}, \mathrm{H}-1_{\mathrm{B}}\right), 4.36-4.32$ ( $\mathrm{m}, 4 \mathrm{H}, \mathrm{H}-2_{\mathrm{C}}, \mathrm{PhCH}_{2}$ ), 4.22 (d, J= $11.5 \mathrm{~Hz}, 1$ $\left.\mathrm{H}, \mathrm{PhCH}_{2}\right), 4.09-4.01\left(\mathrm{~m}, 4 \mathrm{H}, \mathrm{H}-2_{\mathrm{A}}, \mathrm{H}-3_{\mathrm{B}}, \mathrm{H}-5_{\mathrm{A}}, \mathrm{H}-5_{\mathrm{B}}\right.$ ), 3.98 (dd, $J=$ $\left.10.5,3.0 \mathrm{~Hz}, 1 \mathrm{H}, \mathrm{H}-3_{\mathrm{C}}\right), 3.96-3.87$ ( $\mathrm{m}, 3 \mathrm{H}, \mathrm{H}-3_{\mathrm{A}}, \mathrm{H}-4_{\mathrm{A}}, \mathrm{H}-4_{\mathrm{B}}$ ), 3.82- 
$3.80\left(\mathrm{~m}, 1 \mathrm{H}, \mathrm{H}-5_{\mathrm{c}}\right), 3.72\left(\mathrm{~s}, 3 \mathrm{H}, \mathrm{OCH}_{3}\right), 3.67(\mathrm{dd}, J=10.5,3.0 \mathrm{~Hz}, 1 \mathrm{H}$, $\left.\mathrm{H}-2_{\mathrm{B}}\right), 3.58-3.51\left(\mathrm{~m}, 3 \mathrm{H}, \mathrm{H}-6_{\mathrm{abc}}, \mathrm{H}-6_{\mathrm{aA}}\right), 3.42-3.35$ ( $\mathrm{m}, 1 \mathrm{H}, \mathrm{H}-6_{\mathrm{aB}}$ ), 3.34-3.26 ( $\left.\mathrm{m}, 2 \mathrm{H}, \mathrm{H}-6_{\mathrm{bA}}, \mathrm{H}-6_{\mathrm{bB}}\right), 2.05\left(\mathrm{~s}, 3 \mathrm{H}, \mathrm{COCH}_{3}\right)$.

${ }^{13} \mathrm{C}$ NMR (125 MHz, $\left.\mathrm{CDCl}_{3}\right): \delta=171.5\left(\mathrm{COCH}_{3}\right), 167.7,167.4$ (PhthCO), 155.0-114.4 (m, Ar-C), 99.9 (C-1 $\mathrm{C}_{\mathrm{C}}, 97.8\left(\mathrm{C}-1_{\mathrm{B}}\right), 97.7\left(\mathrm{C}-1_{\mathrm{A}}\right), 78.8(\mathrm{C}-$ $\left.5_{\mathrm{A}}\right), 78.7\left(\mathrm{C}-5_{\mathrm{B}}\right), 76.7\left(\mathrm{C}-3_{\mathrm{A}}\right), 76.3\left(\mathrm{C}-2_{\mathrm{B}}\right), 75.6\left(\mathrm{C}-3_{\mathrm{B}}\right), 75.2\left(\mathrm{C}-2_{\mathrm{A}}\right), 74.6$ $\left(\mathrm{PhCH}_{2}\right), 74.4\left(\mathrm{PhCH}_{2}\right), 73.5\left(\mathrm{PhCH}_{2}\right), 73.3\left(\mathrm{PhCH}_{2}\right), 73.2\left(\mathrm{PhCH}_{2}\right), 73.1$ $\left(\mathrm{PhCH}_{2}\right), 72.8\left(\mathrm{PhCH}_{2}\right), 71.8\left(\mathrm{C}-4_{\mathrm{B}}\right), 70.2\left(\mathrm{C}-4_{\mathrm{A}}\right), 69.9\left(\mathrm{C}-3_{\mathrm{C}}\right), 69.1\left(\mathrm{C}-4_{\mathrm{C}}\right)$, $69.0\left(\mathrm{C}-6_{\mathrm{B}}\right), 67.8\left(\mathrm{C}-6_{\mathrm{A}}\right), 67.2\left(\mathrm{C}-5_{\mathrm{C}}\right), 67.1\left(\mathrm{C}-6_{\mathrm{C}}\right), 55.5\left(\mathrm{OCH}_{3}\right), 54.8(\mathrm{C}-$ $2 \mathrm{C}), 20.8\left(\mathrm{COCH}_{3}\right)$.

MALDI-MS: $1434.5[\mathrm{M}+\mathrm{Na}]^{+}$.

Anal. Calcd for $\mathrm{C}_{84} \mathrm{H}_{85} \mathrm{NO}_{19}$ (1411.57): C, 71.42; H, 6.07. Found: C, 71.25; H, 6.27.

\section{4-Methoxyphenyl (3-0-Acetyl-2-azido-4,6-0-benzylidene-2-de- oxy- $\alpha$-D-galactopyranosyl)-(1 $\rightarrow 3)$-[4-0-acetyl-6-0-benzyl-2-de- oxy-2-( $N$-phthalimido)- $\beta$-D-galactopyranosyl]-(1 $\rightarrow 3)-(2,4,6-$ tri- $O$ - benzyl- $\alpha$-D-galactopyranosyl)-( $1 \rightarrow 6)-2,3,4$-tri-O-benzyl- $\alpha$-D-galac- topyranoside (13)}

MS-4Å (2 g) were added to a solution of compound 12 (900 mg, 0.64 $\mathrm{mmol}$ ) and compound 5 (700 $\mathrm{mg}, 1.58 \mathrm{mmol}$ ) in anhyd $1: 3 \mathrm{CH}_{2} \mathrm{Cl}_{2}-$ $\mathrm{Et}_{2} \mathrm{O}(15 \mathrm{~mL})$, and reaction mixture was cooled to $0{ }^{\circ} \mathrm{C}$ under argon. The cooled mixture was treated with NIS $(360 \mathrm{~g}, 1.6 \mathrm{mmol})$ and TMSOTf $(5 \mu \mathrm{L})$ then stirred at $0{ }^{\circ} \mathrm{C}$ for $45 \mathrm{~min}$. The mixture was then diluted with $\mathrm{CH}_{2} \mathrm{Cl}_{2}(100 \mathrm{~mL})$ and washed successively with $5 \%$ aq $\mathrm{Na}_{2} \mathrm{~S}_{2} \mathrm{O}_{3}(50 \mathrm{~mL})$, sat. aq $\mathrm{NaHCO}_{3}(100 \mathrm{~mL})$, and $\mathrm{H}_{2} \mathrm{O}(100 \mathrm{~mL})$, then dried $\left(\mathrm{Na}_{2} \mathrm{SO}_{4}\right)$ and concentrated under reduced pressure. The crude product was purified by chromatography [silica gel, hexane-EtOAc (4:1)] to a white solid; yield: $750 \mathrm{mg}(68 \%) ; \mathrm{mp} 93-94{ }^{\circ} \mathrm{C}(\mathrm{EtOH})$; $[\alpha]_{\mathrm{D}}^{23}+101\left(\right.$ c $\left.1.0, \mathrm{CHCl}_{3}\right)$.

IR (KBr): 2937, 1749, 1510, 1371, 1229, 1088, 1050, 827, $759 \mathrm{~cm}^{-1}$.

${ }^{1} \mathrm{H}$ NMR $\left(500 \mathrm{MHz}, \mathrm{CDCl}_{3}\right): \delta=7.49-6.76(\mathrm{~m}, 48 \mathrm{H}, \mathrm{Ar}-\mathrm{H}), 5.66(\mathrm{~d}, J=$ $\left.3.0 \mathrm{~Hz}, 1 \mathrm{H}, \mathrm{H}-4_{\mathrm{C}}\right), 5.49$ (d, J = 8.0 Hz, $\left.1 \mathrm{H}, \mathrm{H}-1_{\mathrm{C}}\right), 5.28$ (d, J = $2.0 \mathrm{~Hz}, 1 \mathrm{H}$, $\left.\mathrm{H}-1_{\mathrm{A}}\right), 5.23(\mathrm{~s}, 1 \mathrm{H}, \mathrm{PhCH}), 5.11$ (d, $\left.J=3.5 \mathrm{~Hz}, 1 \mathrm{H}, \mathrm{H}-1_{\mathrm{D}}\right), 4.96(\mathrm{~d}, J=$ $\left.11.5 \mathrm{~Hz}, 1 \mathrm{H}, \mathrm{PhCH}_{2}\right), 4.86\left(\mathrm{~d}, J=11.5 \mathrm{~Hz}, 1 \mathrm{H}, \mathrm{PhCH}_{2}\right), 4.82(\mathrm{dd}, J=$ 10.0, 3.0 Hz, $\left.1 \mathrm{H}, \mathrm{H}-3_{\mathrm{D}}\right), 4.81-4.70\left(\mathrm{~m}, 4 \mathrm{H}, \mathrm{PhCH}_{2}\right), 4.69-4.58(\mathrm{~m}, 3 \mathrm{H}$, $\left.\mathrm{H}-2_{\mathrm{C}}, \mathrm{PhCH}_{2}\right), 4.48$ (d, J = 11.5 Hz, $\left.1 \mathrm{H}, \mathrm{PhCH}_{2}\right), 4.41$ (d, $J=3.0 \mathrm{~Hz}, 1 \mathrm{H}$, $\left.\mathrm{H}-1_{\mathrm{B}}\right), 4.40-4.23\left(5 \mathrm{~d}, J=11.5 \mathrm{~Hz}\right.$ each, $\left.5 \mathrm{H}, \mathrm{PhCH}_{2}\right), 4.09-4.04(\mathrm{~m}, 5 \mathrm{H}$, $\left.\mathrm{H}-2_{\mathrm{A}}, \mathrm{H}-3_{\mathrm{B}}, \mathrm{H}-4_{\mathrm{D}}, \mathrm{H}-5_{\mathrm{A}}, \mathrm{H}-5_{\mathrm{B}}\right), 3.99-3.90\left(\mathrm{~m}, 4 \mathrm{H}, \mathrm{H}-2_{\mathrm{D}}, \mathrm{H}-3_{\mathrm{A}}, \mathrm{H}-3_{\mathrm{C}}, \mathrm{H}-\right.$ $4_{\mathrm{A}}$ ), 3.87 (br s, $1 \mathrm{H}, \mathrm{H}-4_{\mathrm{B}}$ ), $3.82-3.80\left(\mathrm{~m}, 1 \mathrm{H}, \mathrm{H}-5_{\mathrm{C}}\right), 3.73\left(\mathrm{~s}, 3 \mathrm{H}, \mathrm{OCH}_{3}\right)$, 3.70 (dd, $\left.J=10.0,3.0 \mathrm{~Hz}, 1 \mathrm{H}, \mathrm{H}-2_{\mathrm{B}}\right), 3.60-3.50$ (m, $4 \mathrm{H}, \mathrm{H}-6_{\mathrm{abc}}, \mathrm{H}-6_{\mathrm{abD}}$ ), 3.47-3.37 (m, $\left.2 \mathrm{H}, \mathrm{H}-6_{\mathrm{aA}}, \mathrm{H}-6_{\mathrm{aB}}\right), 3.18-3.17$ ( $\left.\mathrm{m}, 1 \mathrm{H}, \mathrm{H}-5_{\mathrm{D}}\right), 2.11,2.06$ $\left(2 \mathrm{~s}, 6 \mathrm{H}, 2 \mathrm{COCH}_{3}\right)$.

${ }^{13} \mathrm{C}$ NMR $\left(125 \mathrm{MHz}, \mathrm{CDCl}_{3}\right): \delta=170.1,169.9\left(2 \mathrm{COCH}_{3}\right), 167.7,167.4$ (PhthCO), 155.0-114.5 (m, Ar-C), 100.6 (PhCH), 99.8 (C-1 $\mathrm{C}$ ), 97.8 (2 C, C $\left.-1_{A}, C-1_{B}\right), 97.0\left(C-1_{D}\right), 78.8\left(2 \mathrm{C}, C-5_{A}, C-5_{B}\right), 76.4\left(C-3_{A}\right), 76.3\left(C-2_{B}\right)$, $75.5\left(\mathrm{C}-2_{\mathrm{A}}\right), 75.2\left(\mathrm{C}-3_{\mathrm{B}}\right), 74.5\left(2 \mathrm{C}, 2 \mathrm{PhCH}_{2}\right), 73.6\left(\mathrm{PhCH}_{2}\right), 73.5$ $\left(\mathrm{PhCH}_{2}\right), 73.3\left(2 \mathrm{C}, \mathrm{PhCH}_{2}\right), 73.1\left(\mathrm{C}-4_{\mathrm{A}}\right), 73.0\left(\mathrm{C}-4_{\mathrm{D}}\right), 72.9\left(\mathrm{PhCH}_{2}\right), 72.6$ $\left(\mathrm{C}-4_{\mathrm{B}}\right), 69.8\left(\mathrm{C}-3_{\mathrm{D}}\right), 69.7\left(\mathrm{C}-3_{\mathrm{C}}\right), 69.2\left(\mathrm{C}-4_{\mathrm{C}}\right), 69.1\left(\mathrm{C}-6_{\mathrm{D}}\right), 68.3\left(2 \mathrm{C}, \mathrm{C}-6_{\mathrm{A}}\right.$, C- $\left.6_{B}\right), 67.0\left(C-6_{C}\right), 66.4\left(C-5_{C}\right), 62.9\left(C-5_{D}\right), 57.2\left(C-2_{D}\right), 55.5\left(\mathrm{OCH}_{3}\right)$, $53.4\left(\mathrm{C}-2_{\mathrm{C}}\right), 20.9,20.7\left(2 \mathrm{COCH}_{3}\right)$.

MALDI-MS: $1751.6[\mathrm{M}+\mathrm{Na}]^{+}$.

Anal. Calcd for $\mathrm{C}_{99} \mathrm{H}_{100} \mathrm{~N}_{4} \mathrm{O}_{24}$ (1728.67): C, 68.74; H, 5.83. Found: C, $68.60 ; \mathrm{H}, 6.00$.
4-Methoxyphenyl (2-Azido-4,6-0-benzylidene-2-deoxy- $\alpha$-D-galactopyranosyl)-(1 $\rightarrow 3)$-[4-O-acetyl-6-O-benzyl-2-deoxy-2-( $N$-phthalimido)- $\beta$-D-galactopyranosyl]-( $1 \rightarrow 3)-(2,4,6$-tri-O-benzyl- $\alpha$-Dgalactopyranosyl)-(1 $\rightarrow 6)-2,3,4$-tri-O-benzyl- $\alpha$-D-galactopyranoside (14)

A solution of compound $\mathbf{1 0}$ (700 $\mathrm{mg}, 0.40 \mathrm{mmol})$ in $0.1 \mathrm{M}$ methanolic $\mathrm{NaOMe}(20 \mathrm{~mL})$ was stirred at r.t. for $1.5 \mathrm{~h}$. The mixture was then neutralized with Dowex 50W X8 $\left(\mathrm{H}^{+}\right)$, filtered, and concentrated under reduced pressure. The crude product was passed through a short pad of silica gel with elution by hexane-EtOAc $(2: 1)$ to give a white solid; yield: $650 \mathrm{mg}(95 \%) ; \mathrm{mp} 95-96^{\circ} \mathrm{C}(\mathrm{EtOH}) ;[\alpha]_{\mathrm{D}}^{23}+61\left(\mathrm{c} 1.0, \mathrm{CHCl}_{3}\right)$.

IR (KBr): 2927, 1746, 1508, 1456, 1369, 1233, 1109, 1055, 987, 826, $739 \mathrm{~cm}^{-1}$.

${ }^{1} \mathrm{H}$ NMR $\left(500 \mathrm{MHz}, \mathrm{CDCl}_{3}\right): \delta=7.45-6.76(\mathrm{~m}, 48 \mathrm{H}, \mathrm{Ar}-\mathrm{H}), 5.66(\mathrm{~d}, J=$ $\left.3.0 \mathrm{~Hz}, 1 \mathrm{H}, \mathrm{H}-4_{\mathrm{C}}\right), 5.47$ (d, J = 8.5 Hz, $\left.1 \mathrm{H}, \mathrm{H}-1_{\mathrm{C}}\right), 5.27$ (s, $1 \mathrm{H}, \mathrm{PhCH}$ ), $5.26\left(\mathrm{~d}, J=2.5 \mathrm{~Hz}, 1 \mathrm{H}, \mathrm{H}-1_{\mathrm{A}}\right), 5.09\left(\mathrm{~d}, J=3.0 \mathrm{~Hz}, 1 \mathrm{H}, \mathrm{H}-1_{\mathrm{D}}\right), 4.95-4.69$ $\left(6 \mathrm{~d}, J=11.5 \mathrm{~Hz}\right.$ each, $\left.6 \mathrm{H}, \mathrm{PhCH}_{2}\right), 4.65-4.58\left(\mathrm{~m}, 4 \mathrm{H}, \mathrm{H}-2_{\mathrm{C}}, \mathrm{PhCH}_{2}\right)$, 4.45 (d, $\left.J=11.5 \mathrm{~Hz}, 1 \mathrm{H}, \mathrm{PhCH}_{2}\right), 4.40$ (d, J = 11.5 Hz, $\left.1 \mathrm{H}, \mathrm{PhCH}_{2}\right), 4.38$ (d, $\left.J=3.0 \mathrm{~Hz}, 1 \mathrm{H}, \mathrm{H}-1_{\mathrm{B}}\right), 4.35-4.22\left(3 \mathrm{~d}, J=11.5 \mathrm{~Hz}\right.$ each, $3 \mathrm{H}, \mathrm{PhCH}_{2}$ ), 4.07-4.00 (m, $\left.4 \mathrm{H}, \mathrm{H}-2_{\mathrm{A}}, \mathrm{H}-3_{\mathrm{B}}, \mathrm{H}-5_{\mathrm{A}}, \mathrm{H}-5_{\mathrm{B}}\right), 3.99-3.95\left(\mathrm{~m}, 2 \mathrm{H}, \mathrm{H}-3_{\mathrm{C}}, \mathrm{H}-\right.$ $\left.4_{\mathrm{D}}\right), 3.92-3.84\left(\mathrm{~m}, 2 \mathrm{H}, \mathrm{H}-3_{\mathrm{A}}, \mathrm{H}-3_{\mathrm{D}}\right), 3.82-3.75\left(\mathrm{~m}, 3 \mathrm{H}, \mathrm{H}-4_{\mathrm{A}}, \mathrm{H}-4_{\mathrm{B}}, \mathrm{H}-\right.$ 5 $), 3.73\left(\mathrm{~s}, 3 \mathrm{H}, \mathrm{OCH}_{3}\right), 3.66\left(\mathrm{~d}, J=10.0,3.0 \mathrm{~Hz}, 1 \mathrm{H}, \mathrm{H}-2_{\mathrm{B}}\right), 3.62-3.60$ $\left(\mathrm{m}, 1 \mathrm{H}, \mathrm{H}-6_{\mathrm{aD}}\right), 3.58-3.48\left(\mathrm{~m}, 4 \mathrm{H}, \mathrm{H}-2_{\mathrm{D}}, \mathrm{H}-6_{\mathrm{abc}}, \mathrm{H}-6_{\mathrm{bD}}\right), 3.43-3.35$ (m, $\left.2 \mathrm{H}, \mathrm{H}-6_{\mathrm{aA}}, \mathrm{H}-6_{\mathrm{aB}}\right), 3.32-3.25\left(\mathrm{~m}, 2 \mathrm{H}, \mathrm{H}-6_{\mathrm{bA}}, \mathrm{H}-6_{\mathrm{bB}}\right), 3.12-3.11(\mathrm{~m}, 1 \mathrm{H}$, $\left.\mathrm{H}-5_{\mathrm{D}}\right), 2.10\left(\mathrm{~s}, 3 \mathrm{H}, \mathrm{COCH}_{3}\right)$.

${ }^{13} \mathrm{C}$ NMR (125 MHz, $\left.\mathrm{CDCl}_{3}\right): \delta=171.2\left(\mathrm{COCH}_{3}\right), 167.7,167.4$ (PhthCO), 155.2-114.5 (m, Ar-C), $101.1(\mathrm{PhCH}), 99.8\left(\mathrm{C}-1_{\mathrm{C}}\right), 97.7$ (2 C, C-1 $\mathrm{A}, \mathrm{C}-$ $\left.1_{B}\right), 96.6\left(C-1_{D}\right), 78.8\left(2 C, C-5_{A}, C-5_{B}\right), 76.7\left(C-5_{C}\right), 76.3\left(C-3_{A}\right), 75.5(C-$ $\left.2_{\mathrm{B}}\right), 75.1\left(\mathrm{C}-2_{\mathrm{A}}\right), 74.9\left(\mathrm{C}-3_{\mathrm{B}}\right), 74.5\left(2 \mathrm{C}, 2 \mathrm{PhCH}_{2}\right), 73.6\left(\mathrm{PhCH}_{2}\right), 73.3$ $\left(\mathrm{PhCH}_{2}\right), 73.1\left(2 \mathrm{C}, 2 \mathrm{PhCH}_{2}\right), 72.5\left(\mathrm{PhCH}_{2}\right), 72.4\left(\mathrm{C}-4_{\mathrm{A}}\right), 72.3\left(\mathrm{C}-4_{\mathrm{D}}\right)$, $69.8\left(C-4_{B}\right), 69.1\left(C-3_{D}\right), 69.0\left(C-6_{D}\right), 68.5\left(C-6_{A}\right), 68.3\left(C-6_{B}\right), 67.6(C-$ 3 $), 67.0\left(\mathrm{C}-6_{\mathrm{C}}\right), 66.0\left(\mathrm{C}-4_{\mathrm{C}}\right), 63.1\left(\mathrm{C}-5_{\mathrm{D}}\right), 60.7\left(\mathrm{C}-2_{\mathrm{D}}\right), 55.5\left(\mathrm{OCH}_{3}\right), 53.3$ $\left(\mathrm{C}-2_{\mathrm{C}}\right), 20.7\left(\mathrm{COCH}_{3}\right)$.

MALDI-MS: $1709.6[\mathrm{M}+\mathrm{Na}]^{+}$.

Anal. Calcd for $\mathrm{C}_{97} \mathrm{H}_{98} \mathrm{~N}_{4} \mathrm{O}_{23}$ (1686.66): C, 69.03; H, 5.85. Found: C, $68.84 ; \mathrm{H}, 6.00$.

4-Methoxyphenyl (2,3-O-Benzoyl-4,6-O-benzylidene- $\beta$-D-glucopyranosyl)-( $1 \rightarrow 3)$-(2-azido-4,6-0-benzylidene-2-deoxy- $\alpha$-D-galactopyranosyl)-(1 $\rightarrow 3)$-[4-0-acetyl-6-O-benzyl-2-deoxy-2-( $N$-phthalimido)- $\beta$-D-galactopyranosyl]-( $1 \rightarrow 3)-(2,4,6$-tri- $O$-benzyl- $\alpha$-D-galactopyranosyl)-( $1 \rightarrow 6)-2,3,4$-tri-O-benzyl- $\alpha$-D-galactopyranoside (15)

MS-4Å (500 mg) were added to a solution of compound 14 (600 mg, $0.36 \mathrm{mmol})$ and compound $\mathbf{6}(225 \mathrm{mg}, 0.43 \mathrm{mmol})$ in anhyd $\mathrm{CH}_{2} \mathrm{Cl}_{2}(5$ $\mathrm{mL}$ ), and the mixture was cooled to $-20^{\circ} \mathrm{C}$ under argon. NIS (100 mg, $0.44 \mathrm{mmol})$ and TMSOTf $(3 \mu \mathrm{L})$ were added and the mixture was stirred at $-20{ }^{\circ} \mathrm{C}$ for $30 \mathrm{~min}$. The mixture was then diluted with $\mathrm{CH}_{2} \mathrm{Cl}_{2}(50 \mathrm{~mL})$ and washed successively with $5 \%$ aq $\mathrm{Na}_{2} \mathrm{~S}_{2} \mathrm{O}_{3}(25 \mathrm{~mL})$, sat. aq $\mathrm{NaHCO}_{3}(50 \mathrm{~mL})$, and $\mathrm{H}_{2} \mathrm{O}(50 \mathrm{~mL})$. The organic phase was dried $\left(\mathrm{Na}_{2} \mathrm{SO}_{4}\right)$ and concentrated under reduced pressure to give a crude product that was purified by chromatography [silica gel, hexane-EtOAc (4:1)] to give a white solid; yield: $550 \mathrm{mg}(72 \%)$; $\mathrm{mp}$ $162-163{ }^{\circ} \mathrm{C}(\mathrm{EtOH}) ;[\alpha]_{\mathrm{D}}{ }^{23}+72\left(c 1.0, \mathrm{CHCl}_{3}\right)$.

IR (KBr): 2932, 1776, 1748, 1720, 1509, 1388, 1229, 1107, 1081, 1052 , $1029,998,827,738,722 \mathrm{~cm}^{-1}$.

${ }^{1} \mathrm{H}$ NMR $\left(500 \mathrm{MHz}, \mathrm{CDCl}_{3}\right): \delta=7.89-6.70(\mathrm{~m}, 63 \mathrm{H}, \mathrm{Ar}-\mathrm{H}), 5.64(\mathrm{t}, J=$ $\left.8.5 \mathrm{~Hz}, 1 \mathrm{H}, \mathrm{H}-2_{\mathrm{E}}\right), 5.56\left(\mathrm{~d}, J=3.0 \mathrm{~Hz}, 1 \mathrm{H}, \mathrm{H}-4_{\mathrm{C}}\right), 5.44(\mathrm{~d}, J=8.5 \mathrm{~Hz}, 1 \mathrm{H}$, $\left.\mathrm{H}-1_{\mathrm{C}}\right), 5.40\left(\mathrm{t}, J=9.0 \mathrm{~Hz}, 1 \mathrm{H}, \mathrm{H}-3_{\mathrm{E}}\right), 5.37(\mathrm{~s}, 1 \mathrm{H}, \mathrm{PhCH}), 5.21(\mathrm{~d}, J=2.5$ $\left.\mathrm{Hz}, 1 \mathrm{H}, \mathrm{H}-1_{\mathrm{A}}\right), 5.19$ (s, $\left.1 \mathrm{H}, \mathrm{PhCH}\right), 4.97$ (d, J = 3.0 Hz, $\left.1 \mathrm{H}, \mathrm{H}-1_{\mathrm{D}}\right), 4.95$ 
$\left(\mathrm{d}, J=8.5 \mathrm{~Hz}, 1 \mathrm{H}, \mathrm{H}-1_{\mathrm{E}}\right), 4.91-4.52\left(8 \mathrm{~d}, J=11.5 \mathrm{~Hz}\right.$ each, $\left.8 \mathrm{H}, \mathrm{PhCH}_{2}\right)$, 4.51 (t, J = 8.5 Hz, $1 \mathrm{H}, \mathrm{H}-2_{\mathrm{C}}$ ), 4.41 (d, J=11.5 Hz, $1 \mathrm{H}, \mathrm{PhCH}_{2}$ ), 4.34 (d, $\left.J=3.0 \mathrm{~Hz}, 1 \mathrm{H}, \mathrm{H}-1_{\mathrm{B}}\right), 4.32-4.27\left(\mathrm{~m}, 4 \mathrm{H}, \mathrm{PhCH}_{2}\right), 4.26-4.21(\mathrm{~m}, 1 \mathrm{H}, \mathrm{H}-$ $\left.6_{\mathrm{aE}}\right), 4.17\left(\mathrm{~d}, J=11.5 \mathrm{~Hz}, 1 \mathrm{H}, \mathrm{PhCH}_{2}\right), 4.02-3.96\left(\mathrm{~m}, 5 \mathrm{H}, \mathrm{H}-2_{\mathrm{A}}, \mathrm{H}-3_{\mathrm{B}}, \mathrm{H}-\right.$ $\left.5_{\mathrm{A}}, \mathrm{H}-5_{\mathrm{B}}, \mathrm{H}-5_{\mathrm{E}}\right), 3.92-3.89\left(\mathrm{~m}, 3 \mathrm{H}, \mathrm{H}-3_{\mathrm{A}}, \mathrm{H}-3_{\mathrm{C}}, \mathrm{H}-4_{\mathrm{D}}\right), 3.85-3.80$ (m, 2 $\left.\mathrm{H}, \mathrm{H}-3_{\mathrm{D}}, \mathrm{H}-4_{\mathrm{A}}\right), 3.78-3.62\left(\mathrm{~m}, 6 \mathrm{H}, \mathrm{H}-2_{\mathrm{B}}, \mathrm{H}-2_{\mathrm{D}}, \mathrm{H}-4_{\mathrm{B}}, \mathrm{H}-4_{\mathrm{E}}, \mathrm{H}-5_{\mathrm{C}}, \mathrm{H}-6_{\mathrm{bE}}\right.$ ), $3.72\left(\mathrm{~s}, 3 \mathrm{H}, \mathrm{OCH}_{3}\right), 3.55-3.46\left(\mathrm{~m}, 4 \mathrm{H}, \mathrm{H}-6_{\mathrm{aA}}, \mathrm{H}-6_{\mathrm{abc}}, \mathrm{H}-6_{\mathrm{aD}}\right), 3.43-3.40$ $\left(\mathrm{m}, 1 \mathrm{H}, \mathrm{H}-6_{\mathrm{bD}}\right), 3.38-3.32\left(\mathrm{~m}, 1 \mathrm{H}, \mathrm{H}-6_{\mathrm{aB}}\right), 3.30-3.20\left(\mathrm{~m}, 2 \mathrm{H}, \mathrm{H}-6_{\mathrm{bA}}, \mathrm{H}-\right.$ $\left.6_{\mathrm{bB}}\right), 3.06-3.05\left(\mathrm{~m}, 1 \mathrm{H}, \mathrm{H}-5_{\mathrm{D}}\right), 1.95\left(\mathrm{~s}, 3 \mathrm{H}, \mathrm{COCH}_{3}\right)$.

${ }^{13} \mathrm{C}$ NMR $\left(125 \mathrm{MHz}, \mathrm{CDCl}_{3}\right): \delta=171.0\left(\mathrm{COCH}_{3}\right), 167.7,167.4$ (PhthCO), 165.7, 165.3 (2 PhCO), 155.1-114.5 (m, Ar-C), 102.1 (C-1 $\left.1_{\mathrm{E}}\right), 101.6$ ( $\mathrm{PhCH}), 100.4(\mathrm{PhCH}), 99.7\left(\mathrm{C}-1_{\mathrm{C}}\right), 97.7\left(\mathrm{C}-1_{\mathrm{A}}\right), 97.6\left(\mathrm{C}-1_{\mathrm{B}}\right), 97.2\left(\mathrm{C}-1_{\mathrm{D}}\right)$, $78.8\left(2 \mathrm{C}, \mathrm{C}-5_{\mathrm{A}}, \mathrm{C}-5_{\mathrm{B}}\right), 78.4\left(\mathrm{C}-5_{\mathrm{E}}\right), 76.7\left(\mathrm{C}-5_{\mathrm{C}}\right), 76.3\left(\mathrm{C}-3_{\mathrm{A}}\right), 75.4(2 \mathrm{C}, \mathrm{C}-$ $\left.2_{\mathrm{A}}, \mathrm{C}-2_{\mathrm{B}}\right), 75.2\left(\mathrm{C}-3_{\mathrm{B}}\right), 74.9\left(\mathrm{C}-3_{\mathrm{E}}\right), 74.5\left(2 \mathrm{C}, 2 \mathrm{PhCH}_{2}\right), 73.6\left(\mathrm{PhCH}_{2}\right)$, $73.3\left(\mathrm{PhCH}_{2}\right), 73.1\left(2 \mathrm{C}, 2 \mathrm{PhCH}_{2}\right), 72.7\left(\mathrm{C}-2_{\mathrm{E}}\right), 72.5\left(\mathrm{PhCH}_{2}\right), 72.3(2 \mathrm{C}$, C- $\left.4_{A}, C-4_{E}\right), 72.2\left(C-4_{D}\right), 69.8\left(C-4_{B}\right), 69.1\left(C-3_{D}\right), 69.0\left(C-6_{D}\right), 68.6(C-$ $\left.6_{\mathrm{E}}\right), 68.2\left(\mathrm{C}-6_{\mathrm{A}}\right), 68.0\left(\mathrm{C}-6_{\mathrm{B}}\right), 67.0\left(\mathrm{C}-6_{\mathrm{C}}\right), 66.4\left(2 \mathrm{C}, \mathrm{C}-3_{\mathrm{C}}, \mathrm{C}-4_{\mathrm{C}}\right), 63.5(\mathrm{C}-$ $\left.5_{\mathrm{D}}\right), 59.2\left(\mathrm{C}-2_{\mathrm{D}}\right), 55.5\left(\mathrm{OCH}_{3}\right), 53.5\left(\mathrm{C}-2_{\mathrm{C}}\right), 20.7\left(\mathrm{COCH}_{3}\right)$.

MALDI-MS: $2167.7[\mathrm{M}+\mathrm{Na}]^{+}$.

Anal. Calcd for $\mathrm{C}_{124} \mathrm{H}_{120} \mathrm{~N}_{4} \mathrm{O}_{30}$ (2144.80): C, 69.39; H, 5.64. Found: C, $69.23 ; \mathrm{H}, 5.85$.

\section{4-Methoxyphenyl ( $\beta$-D-glucopyranosyl)-( $1 \rightarrow 3)$-(2-acetamido-2- deoxy- $\alpha$-D-galactopyranosyl)-( $\rightarrow 3)$-(2-acetamido-2-deoxy- $\beta$ - $D$ - galactopyranosyl)-( $(\rightarrow 3)$-( $\alpha$-D-galactopyranosyl)-( $1 \rightarrow 6)$ - $\alpha$-D-galac- topyranoside (1)}

$\mathrm{NH}_{2} \mathrm{NH}_{2} \cdot \mathrm{H}_{2} \mathrm{O}(0.3 \mathrm{~mL})$ was added to a solution of compound $\mathbf{1 5}$ (500 $\mathrm{mg}, 0.23 \mathrm{mmol})$ in EtOH $(15 \mathrm{~mL})$, and the mixture was stirred at $80^{\circ} \mathrm{C}$ for $10 \mathrm{~h}$. The solvents were removed under reduced pressure, the crude product was dissolved in $\mathrm{Ac}_{2} \mathrm{O}(2 \mathrm{~mL})$ and pyridine $(2 \mathrm{~mL})$, and the solution was kept at r.t. for $1 \mathrm{~h}$. The solvents were removed under reduced pressure to give an acetylated product that was passed through a short pad of silica gel with EtOAc $(50 \mathrm{~mL})$ as eluent. A solution of the purified acetylated in $\mathrm{MeOH}(10 \mathrm{~mL})$ was treated with $20 \%$ $\mathrm{Pd}(\mathrm{OH})_{2} / \mathrm{C}(100 \mathrm{mg})$ under a positive pressure of $\mathrm{H}_{2}$ with stirring at r.t. for $15 \mathrm{~h}$. The mixture was then filtered through a bed of Celite that was washed $\mathrm{MeOH}(30 \mathrm{~mL})$, and the filtrate was concentrated to half of its original volume. $\mathrm{Ac}_{2} \mathrm{O}(1 \mathrm{~mL})$ was added and the mixture was stirred at r.t. for $1 \mathrm{~h}$. The solvents were removed under reduced pressure and a solution of the crude product in $0.1 \mathrm{M}$ methanolic $\mathrm{NaOMe}$ $(10 \mathrm{~mL})$ was stirred at r.t. for $1.5 \mathrm{~h}$. The mixture was neutralized with Dowex 50W X8 $\left(\mathrm{H}^{+}\right)$, filtered, and concentrated to give the crude product that was purified by chromatography [Sephadex LH-20 gel, $\left.\mathrm{MeOH}-\mathrm{H}_{2} \mathrm{O}(3: 1)\right]$ to give 1 as a white powder; $125 \mathrm{mg}(54 \%) ;[\alpha]_{D}{ }^{23}$ $+99\left(\right.$ c 1.0, $\left.\mathrm{H}_{2} \mathrm{O}\right)$.

IR (KBr): 3020, 2928, 1744, 1377, 1220, 1069, $764 \mathrm{~cm}^{-1}$.

${ }^{1} \mathrm{H}$ NMR $\left(500 \mathrm{MHz}, \mathrm{D}_{2} \mathrm{O}\right): \delta=7.02,6.86(2 \mathrm{~d}, J=9.0 \mathrm{~Hz}$ each, $4 \mathrm{H}, \mathrm{Ar}-$ $\mathrm{H}), 5.45\left(\mathrm{~d}, J=4.0 \mathrm{~Hz}, 1 \mathrm{H}, \mathrm{H}-1_{\mathrm{A}}\right), 4.95\left(\mathrm{~d}, J=3.5 \mathrm{~Hz}, 1 \mathrm{H}, \mathrm{H}-1_{\mathrm{D}}\right), 4.70(\mathrm{~d}$, $\left.J=3.5 \mathrm{~Hz}, 1 \mathrm{H}, \mathrm{H}-1_{\mathrm{B}}\right), 4.51\left(\mathrm{~d}, J=8.0 \mathrm{~Hz}, 1 \mathrm{H}, \mathrm{H}-1_{\mathrm{C}}\right), 4.37$ (d, $J=7.5 \mathrm{~Hz}, 1$ $\left.\mathrm{H}, \mathrm{H}-1_{\mathrm{E}}\right), 4.28-4.24$ (m, $\left.1 \mathrm{H}, \mathrm{H}-2_{\mathrm{D}}\right), 4.16-4.09$ ( $\left.\mathrm{m}, 2 \mathrm{H}, \mathrm{H}-3_{\mathrm{A}}, \mathrm{H}-4_{\mathrm{B}}\right), 4.02$ (br s, $1 \mathrm{H}, \mathrm{H}-4_{\mathrm{C}}$ ), 3.98-3.90 (m, $5 \mathrm{H}, \mathrm{H}-2_{\mathrm{A}}, \mathrm{H}-2_{\mathrm{C}}, \mathrm{H}-3_{\mathrm{C}}, \mathrm{H}-4_{\mathrm{A}}, \mathrm{H}-4_{\mathrm{D}}$ ), 3.86-3.81 (m, $\left.1 \mathrm{H}, \mathrm{H}-3_{\mathrm{D}}\right), 3.77-3.56$ ( $\mathrm{m}, 13 \mathrm{H}, \mathrm{H}-2_{\mathrm{B}}, \mathrm{H}-3_{\mathrm{B}}, \mathrm{H}-\mathrm{3}_{\mathrm{E}}, \mathrm{H}-5_{\mathrm{B}}$, H- $\left.6_{\mathrm{abA}}, \mathrm{H}-6_{\mathrm{abB}}, \mathrm{H}-6_{\mathrm{abc}}, \mathrm{H}-6_{\mathrm{abD}}, \mathrm{H}-6_{\mathrm{aE}}\right), 3.68\left(\mathrm{~s}, 3 \mathrm{H}, \mathrm{OCH}_{3}\right), 3.55-3.47(\mathrm{~m}$, $\left.3 \mathrm{H}, \mathrm{H}-5_{\mathrm{A}}, \mathrm{H}-5_{\mathrm{C}}, \mathrm{H}-6_{\mathrm{bE}}\right), 3.35\left(\mathrm{t}, J=8.5 \mathrm{~Hz}, 1 \mathrm{H}, \mathrm{H}-4_{\mathrm{E}}\right), 3.31-3.27(\mathrm{~m}, 2$ $\left.\mathrm{H}, \mathrm{H}-5_{\mathrm{D}}, \mathrm{H}-5_{\mathrm{E}}\right), 3.14\left(\mathrm{t}, J=9.0 \mathrm{~Hz}, 1 \mathrm{H}, \mathrm{H}-2_{\mathrm{E}}\right), 1.90,1.89(2 \mathrm{~s}, 6 \mathrm{H}, 2 \mathrm{CO}-$ $\mathrm{CH}_{3}$ ).

${ }^{13} \mathrm{C}$ NMR $\left(125 \mathrm{MHz}, \mathrm{D}_{2} \mathrm{O}\right): \delta=174.8,174.6\left(2 \mathrm{COCH}_{3}\right), 154.7-115.0(\mathrm{~m}$, $\mathrm{Ar}-\mathrm{C}), 104.3\left(\mathrm{C}-1_{\mathrm{E}}\right), 102.6\left(\mathrm{C}-1_{\mathrm{C}}\right), 98.2\left(2 \mathrm{C}, \mathrm{C}-1_{\mathrm{A}}, \mathrm{C}-1_{\mathrm{B}}\right), 93.8\left(\mathrm{C}-1_{\mathrm{D}}\right)$, $79.5\left(\mathrm{C}-5_{\mathrm{A}}\right), 77.4\left(\mathrm{C}-5_{\mathrm{B}}\right), 75.8\left(2 \mathrm{C}, \mathrm{C}-5_{\mathrm{C}}, \mathrm{C}-5_{\mathrm{E}}\right), 75.6\left(2 \mathrm{C}, \mathrm{C}-3_{\mathrm{D}}, \mathrm{C}-4_{\mathrm{E}}\right)$, $74.7\left(2 \mathrm{C}, \mathrm{C}-3_{\mathrm{B}}, \mathrm{C}-3_{\mathrm{E}}\right), 72.9\left(2 \mathrm{C}, \mathrm{C}-2_{\mathrm{E}}, \mathrm{C}-5_{\mathrm{D}}\right), 71.1\left(\mathrm{C}-4_{\mathrm{D}}\right), 70.0\left(2 \mathrm{C}, \mathrm{C}-3_{\mathrm{C}}\right.$,
$\left.C-4_{B}\right), 69.0\left(C-3_{A}\right), 68.6\left(C-4_{A}\right), 68.0\left(C-2_{B}\right), 67.5\left(C-2_{A}\right), 67.1\left(C-6_{A}\right)$, $63.5\left(\mathrm{C}-4_{\mathrm{C}}\right), 61.0\left(\mathrm{C}-6_{\mathrm{D}}\right), 60.7\left(2 \mathrm{C}, \mathrm{C}-6_{\mathrm{B},} \mathrm{C}-6_{\mathrm{C}}\right), 60.5\left(\mathrm{C}-6_{\mathrm{E}}\right), 56.1\left(\mathrm{OCH}_{3}\right)$, $51.0\left(\mathrm{C}-2_{\mathrm{C}}\right), 48.1\left(\mathrm{C}-2_{\mathrm{D}}\right), 22.5,22.3\left(2 \mathrm{COCH}_{3}\right)$.

ESI-MS: $1039.3[\mathrm{M}+\mathrm{Na}]^{+}$.

Anal. Calcd for $\mathrm{C}_{41} \mathrm{H}_{64} \mathrm{~N}_{2} \mathrm{O}_{27}$ (1016.37): C, 48.42; H, 6.34. Found: $\mathrm{C}$, 48.24; $\mathrm{H}, 6.50$

\section{Acknowledgments}

A.S. thanks CSIR, India, for providing a Junior Research Fellowship. This work was supported by CSIR, New Delhi, [Project no. 02(0038)/11/EMR-II] and the Bose Institute, Kolkata.

\section{Supporting Information}

Supporting information for this article is available online at http://dx.doi.org/10.1055/s-0034-1378911.

\section{References}

(1) Thapar, N.; Sanderson, I. R. Lancet 2004, 363, 641.

(2) Ashbolt, N. J. Toxicology 2004, 198, 229.

(3) Guerrant, R. L.; Hughes, J. M.; Lima, N. L.; Crane, J. Rev. Infect. Dis. 1990, 12, S41.

(4) Nataro, J. P.; Kaper, J. B. Clin. Microbiol. Rev. 1998, 11, 142.

(5) McVeigh, A.; Fasano, A.; Scott, D. A.; Jelacic, S.; Moseley, S. L.; Robertson, D. C.; Savarino, S. J. Infect. Immun. 2000, 68, 5710.

(6) Hussein, H. S.; Sakuma, T. J. Dairy Sci. 2005, 88, 450.

(7) Zhou, Z.; Ogasawara, J.; Nishikawa, Y.; Seto, Y.; Helander, A.; Hase, A.; Iritani, N.; Nakamura, H.; Arikawa, K.; Kai, A.; Kamata, Y.; Hoshi, H.; Haruki, K. Epidemiol. Infect. 2002, 128, 363.

(8) Ali, T.; Weintraub, A.; Widmalm, G. Carbohydr. Res. 2007, 342, 274.

(9) Alanis, A. J. Arch. Med. Res. 2005, 36, 697.

(10) Yan, S.; Ding, N.; Zhang, W.; Wang, P.; Li, Y.; Li, M. Carbohydr. Res. 2012, 354, 6.

(11) Das, S. K.; Ghosh, R.; Roy, N. J. Carbohydr. Chem. 1993, 12, 693.

(12) Santra, A.; Ghosh, T.; Misra, A. K. Tetrahedron: Asymmetry 2012, $23,1385$.

(13) Ziegler, T.; Eckhardt, E.; Strayle, J.; Herzog, H. Carbohydr. Res. 1994, 253, 167.

(14) Panchadhayee, R.; Misra, A. K. Tetrahedron: Asymmetry 2009, 20, 1550.

(15) Panchadhayee, R.; Misra, A. K. Synlett 2010, 1193.

(16) Hudson, C. S.; Dale, I. K. J. Am. Chem. Soc. 1915, 37, 1264.

(17) Konradsson, P.; Udodong, U. E.; Fraser-Reid, B. Tetrahedron Lett. 1990, 31, 4313.

(18) Veeneman, G. H.; van Leeuwen, S. H.; van Boom, J. H. Tetrahedron Lett. 1990, 31, 1331.

(19) Ogawa, T.; Yamamoto, H. Agric. Biol. Chem. 1985, 49, 475.

(20) Zemplén, G. Ber. Dtsch. Chem. Ges. 1926, 59, 1254.

(21) Field, R. A.; Otter, A.; Fu, W.; Hindsgaul, O. Carbohydr. Res. 1995, $276,347$.

(22) Kumar, R.; Maulik, P. R.; Misra, A. K. Glycoconjugate J. 2008, 25, 511.

(23) Lee, H.-H.; Schwartz, D. A.; Harris, J. F.; Carver, J. P.; Krepinsky, J. J. Can. J. Chem. 1986, 64, 1912.

(24) Pearlman, W. M. Tetrahedron Lett. 1967, 8, 1663. 